\title{
Long-term follow-up of patients with previous myocarditis using radionuclide ventriculography
}

\author{
Sunil K. Das, Harry T. Colfer, and Bertram Pitt \\ Division of Cardiology, University of Michigan Medical Center, Ann Arbor, Michigan 48109, USA
}

\begin{abstract}
Summary. A prospective long-term follow-up study is reported of 18 of 19 patients who survived a bout of presumed myocarditis 6-136 months (average 54 months) previously. The study included 14 males and four females, ranging from 27 to 63 years of age (mean, 44 years). Chest X-ray, ECG, echocardiogram, and resting and exercise radionuclide ventricular ejection fraction (RNVEF) for assessment of ventricular function were evaluated at follow-up. Resting and exercise RNVEF from seven control subjects were evaluated for comparison. Residual abnormalities were noted in chest $\mathrm{X}$-ray $(16 \%)$, echocardiogram $(30 \%)$, and ECG $(55 \%)$ in these predominantly asymptomatic patients $(17 / 18$ or $95 \%)$. The resting RNVEF (mean $\pm S D$ ) for the myocarditis group versus controls were $0.57 \pm 0.1$ and $0.65 \pm 0.1$ ( $P$ $=$ NS), respectively. The exercise RNVED for the myocarditis group versus controls were $0.56 \pm 0.1$ and 0.74 $\pm 0.05(P<0.01)$, respectively. Abnormal resting RNVEF was noted in six $(33 \%)$ and exercise RNVEF in $14(77 \%)$ patients in the myocarditis group. Two patients with abnormal exercise RNVEF subsequently developed findings consistent with dilated cardiomyopathy. It is unclear as to whether the abnormal ventricular function may serve as a marker for future development of dilated cardiomyopathy,
\end{abstract}

The outcome in patients surviving a bout of acute myocarditis is generally thought to be benign with little residual functional impairment $[1,2]$. Rare late complications have been recognized, and these include valvular heart disease [3], constrictive pericarditis [4], and sudden death [5]. There is considerable debate as to whether patients with prior myocarditis may eventually develop the typical picture of dilated cardiomyopathy as has been noted in a few patients [6]. In this prospective follow-up study, expanded from an earlier one [7], we have examined clinical data in conjunction with ventricular function using the sensitive technique of radionuclide ventriculography (RNV).

\section{Patients}

Nineteen previously healthy patients, 14 males and five females, with ages ranging from 19 to 60 years (mean, 38
Table 1. Clinical data on 19 subjects with myocarditis

\begin{tabular}{lc}
\hline Presentation & Number \\
\hline Associated upper respiratory illness & 13 \\
Fever & 10 \\
New dyspnea & 16 \\
Chest pain & 8 \\
Palpitation & 8 \\
S gallop & 13 \\
Pericardial friction rub & 2 \\
Hypotension & $2^{\mathrm{a}}$ \\
ECG abnormality & 19 \\
$\quad$ ST-T & $(10)$ \\
$\quad$ Heart block & $(5)$ \\
$\quad$ Arrhythmias & $(13)$ \\
$\quad$ LBBB & $(3)$ \\
RBBB & $(1)$ \\
Chest X-ray (increase CT ratio) & 19
\end{tabular}

One patient died. Autopsy confirmed extensive myocarditis $\angle B B B$ left bundle branch block, $R B B B$ right bundle branch block

years), with a diagnosis of presumed myocarditis, constituted the study population. Clinical data at the time of acute ilness are shown in Table 1. There was an associated upper respiratory illness in 13 patients and symptoms judged to be cardiac in origin were noted in all. Dyspnea was present in 16 patients, chest pain of the nonischemic type in eight, and palpitation in eight; an S3 gallop was present in 13 cases, and a pericardial friction rub in two. Two patients were hypotensive, requiring hemodynamic monitoring and support in the intensive care unit. The ECG was abnormal in all patients: ten with transient ST-T wave abnormality, five with varying degrees of heart block, including two with temporary complete heart block, and in 13 patients arrhythmias (frequent premature ventricular in eight, atrial in eight, transient atrial fibrillation in three, and complete bundle branch blockleft in three and right in one) were observed. Cardiomegaly in chest X-ray was noted in every case. Results of other investigations during illness or convalescence are shown in Table 2. Cardiac enzymes were raised in 6 of 13 patients evaluated. Echocardiography showed increased left ventricular end-diastolic dimension with impaired contraction in three patients. Acute and convalescent viral titers were evaluated in seven patients, two of whom showed rises in 
Table 2. Investigations during illness or convalescence from myocarditis $(n=19)$

\begin{tabular}{lcl}
\hline Parameters & $\begin{array}{l}\text { Number } \\
\text { patients } \\
\text { evaluated }\end{array}$ & $\begin{array}{l}\text { Number } \\
\text { patients } \\
\text { abnormal }\end{array}$ \\
\hline Cardiac enzymes & 13 & 6 \\
Viral titer & 7 & $2^{\mathrm{a}}$ \\
Echocardiography (LV dimension) & 3 & 3 \\
Radionuclide ventriculography & 7 & 6 \\
Gallium-67 myocardial scan & 5 & 1 \\
Thallium-201 scintigraphy & 4 & 0 \\
Myocardial biopsy to detect inflammation & 5 & 0 \\
Coronary arteriograms & 10 & 0 \\
Cardiac catheterization & 13 & 13
\end{tabular}

a Elevation in Coxsackie B and measles virus titers

titers consistent with recent Coxsackie and measles infection, respectively. Primary virus isolation was attempted in four patients, but failed. A gallium-67 myocardial scan was performed in five patients, but was only slightly abnormal in one. Myocardial biopsy in fvie patients failed to show any inflammatory changes. Radionuclide ventricular ejection fraction (RNVEF) was evaluated in seven patients and ranged from 0.15 to 0.50 (mean, 0.34 ). Thirteen patients were evaluated by cardiac catheterization, including ten who underwent coronary arteriography within 12 weeks of their illness. No significant coronary artery disease was noted in any. Left ventricular cineangiography showed impaired contraction in all the ten patients studied. Thallium201 scintigraphy in four patients, including three who did not undergo coronary arteriography, showed no abnormalities of tracer uptake at rest or during exercise. One patient died during the acute stage. Her course was complicated by hypotension and development of acute respiratory distress syndrome and complete heart block. Autopsy confirmed the clinical diagnosis of active myocarditis. The remaining 18 patients who survived improved as they were followed-up periodically. Follow-up evaluation included chest X-ray, ECG, echocardiogram, and resting and exercise RNVEF, carried out 6-136 months (average, 54 months) after an episode of presumed myocarditis.

\section{Method}

The radionuclide ventriculographic studies were carried out in a similar fashion to that described in our earlier study [7]. Data collection was computed according to the method of Strauss et al. [8]. Exercise was initiated at a load of $25 \mathrm{~W}$ until a pedaling rate of $60 \mathrm{rpm}$ was achieved. The load was then progressively increased while maintaining the $60 \mathrm{rpm}$ until the subject became limited by fatigue. Imaging during peak exercise was repeated in the manner described above with the frame rate adjusted for the shorter R-R interval during exercise. During exercise, the ECG, heart rate, and blood pressure were constantly monitored with a physician in attendance $[9,10]$. A semiautomated edge detection algorithm was used to outline the left ventricle in each frame of the baseline resting and exercise studies. These contours were used to define left ventricular regions of interest for each frame. A background region was constructed $1.2 \mathrm{~cm}$ outside the left ventricle in a $60^{\circ}$ arc adjacent to the lateral wall. Background-subtracted left ventricular time-activity curves were generated to determine net end-diastolic counts (EDC) and net end-systolic counts (ESC). The left ventricular ejection fraction (LVEF) was calculated using the followong formula:

$$
\mathrm{LVEF}=\frac{\mathrm{EDC}-\mathrm{ESC}}{\mathrm{EDC}}
$$

A resting LVEF of less than 0.50 or a decrease or increase in LVEF of less than 0.05 with exercise is considered an abnormal response in our laboratory. None of the patients were taking cardiac drugs known to influence ventricular inotropy. Six male and one female subjects, age ranging from 29 to 50 years (mean, 40 years) and without clinical evidence of cardiovascular disease were also evaluated by resting and exercise RNV for comparison.

Statistics. The mean LVEF during rest and exercise were computed in each group and compared for determination of significance using Student's $t$-test.

\section{Results}

The results of the follow-up evaluation are shown in Tables 3 and 4. Except for palpitation in one case, the patients were asymptomatic, and most had returned to their previous occupations. Cardiac examination was normal, except in the two patients who had abnormal splitting of the second heart sound consistent with complete left bundle branch block. Heart size, as assessed by the cardiothoracic ratio, was normal in 15 of 18 patients, with three showing a slight increase. The ECG showed residual ST-T wave abnormality in five patients, persistent complete left bundle branch block in two, new frequent premature ventricular beats in two, and first degree atrioventricular block in one. The left ventricular end-diastolic dimension was increased in 5 of 16 patients, but the percentage fractional shortening in diameter was normal in all as assessed by $\mathbf{M}$-mode echocardiography. The results of the RNV studies are shown in Fig. 1 for the controls and patients; results are expressed as mean LVEF $\pm S D$. The resting mean LVEF for the 18 patients with prior myocarditis was $0.57 \pm 0.1$ compared with $0.65 \pm 0.1$ in the control group. This difference in mean resting LVEF between the two groups was not significant $(P<0.05)$. Six of eighteen patients with prior myocarditis had an abnormal resting LVEF of less than 0.50 (Table 3). The LVEF in seven patients obtained during acute illness had a mean value of 0.33 (range, $0.15-0.50$ ) and increased to a mean of 0.53

Table 3. Follow-up data 6-136 months after myocarditis $(n=18)$

\begin{tabular}{ll}
\hline Parameters & $\begin{array}{l}\text { Number of } \\
\text { patients }\end{array}$ \\
&
\end{tabular}

$\begin{array}{lc}\text { New cardiac symptoms } & 1 \\ \text { Abnormal physical examination } & 2 \\ \text { Chest X-ray (increased CT ratio) } & 3 \\ \text { Abnormal ECG } & 10 \\ \text { Abnormal echocardiogram (LV dimension) } & 5^{\mathrm{a}} \\ \text { Abnormal resting RNV } & 6 \\ \text { Abnormal exercise RNV } & 14\end{array}$

Two patients did not have follow-up echocardiograms 
Table 4. Follow-up data $6-136$ months after myocarditis $(n=18)$

\begin{tabular}{|c|c|c|c|c|c|c|c|c|c|}
\hline \multirow[t]{2}{*}{ Patient } & \multirow{2}{*}{$\begin{array}{l}\text { Cardiac } \\
\text { symptoms }\end{array}$} & \multirow[t]{2}{*}{ Examination } & \multirow{2}{*}{$\begin{array}{l}\mathrm{CT} \\
\text { ratio }\end{array}$} & \multirow[t]{2}{*}{ ECG } & \multicolumn{2}{|c|}{ Echocardiography } & \multicolumn{2}{|c|}{ RNV-EF } & \multirow{2}{*}{$\begin{array}{l}\text { Interval from } \\
\text { myocarditis to } \\
\text { study [months] }\end{array}$} \\
\hline & & & & & $\begin{array}{l}\text { LVIDd } \\
{[\mathrm{cm}]}\end{array}$ & $\begin{array}{l}\% \Delta \mathrm{D} \\
\text { Minor axis }\end{array}$ & Rest & Exercise & \\
\hline 1 & None & $a b n S 2$ & nl & LBBB & 5.6 & 25 & 0.49 & 0.53 & 44 \\
\hline 2 & None & $\mathrm{nl}$ & $\mathrm{nl}$ & $\mathrm{nl}$ & 3.8 & 42 & 0.68 & 0.62 & 25 \\
\hline 3 & None & ni & $\mathrm{nl}$ & ST-T abn & 5.2 & 35 & 0.43 & 0.32 & 84 \\
\hline 4 & None & nl & nl & $\mathrm{nl}$ & 4.8 & 25 & 0.48 & 0.50 & 24 \\
\hline 5 & None & nl & $\mathrm{nl}$ & $\mathrm{nl}$ & 4.6 & 33 & 0.71 & 0.59 & 74 \\
\hline 6 & None & nl & $\mathrm{nl}$ & ST-T abn & 5.4 & 30 & 0.68 & 0.71 & 28 \\
\hline 7 & None & $\mathrm{nl}$ & $\mathrm{nl}$ & nl & - & - & 0.63 & 0.83 & 118 \\
\hline 8 & None & $\mathrm{nl}$ & $\mathrm{nl}$ & ST-T abn & 5.9 & 44 & 0.49 & 0.51 & 70 \\
\hline 9 & None & $\mathrm{nl}$ & $\mathrm{nl}$ & $\mathrm{nl}$ & 4.2 & 26 & 0.62 & 0.67 & 56 \\
\hline 10 & None & nl & Sl incr & nl & 5.4 & 25 & 0.53 & 0.47 & 33 \\
\hline 11 & None & nl & Sl incr & ST-T abn & 5.9 & 25 & 0.45 & 0.47 & 36 \\
\hline 12 & None & nl & $\mathrm{nl}$ & $1^{\circ}$-AVB & 4.8 & 33 & 0.64 & 0.65 & 136 \\
\hline 13 & None & $\mathrm{nl}$ & Sl incr & ST-T abn & 6.1 & .25 & 0.42 & 0.35 & 30 \\
\hline 14 & None & $\mathrm{nl}$ & $\mathrm{nl}$ & $\mathrm{nl}$ & 5.1 & 32 & 0.76 & 0.88 & 72 \\
\hline 15 & None & $\mathrm{nl}$ & $\mathrm{nl}$ & PVB & - & - & 0.52 & 0.46 & 24 \\
\hline 16 & Palpitation & $\mathrm{nl}$ & $\mathrm{nl}$ & PVB & 4.9 & 35 & 0.61 & 0.74 & 27 \\
\hline 17 & None & $\mathrm{nl}$ & $\mathrm{nl}$ & $\mathrm{nl}$ & 6.0 & 27 & 0.65 & 0.61 & 9 \\
\hline 18 & None & abn $\mathrm{S} 2$ & $\mathrm{nl}$ & LBBB & 5.8 & 29 & 0.54 & 0.35 & 6 \\
\hline
\end{tabular}

$a b n$ abnormal, A-fib = atrial fibrillation, $\% \Delta D$ percentage fractional shortening, $L B B B$ left bundle branch block, $L V I D d$ left ventricular internal diameter in diastole, $n l$ normal, $P V B$ premature ventricular beat, $R N V-E F$ radionuclide ventricular ejection fraction, $S 2$ second heart sound, $S l$ incr slight increase, $I^{\circ} A V B$ first degree atrioventricular block
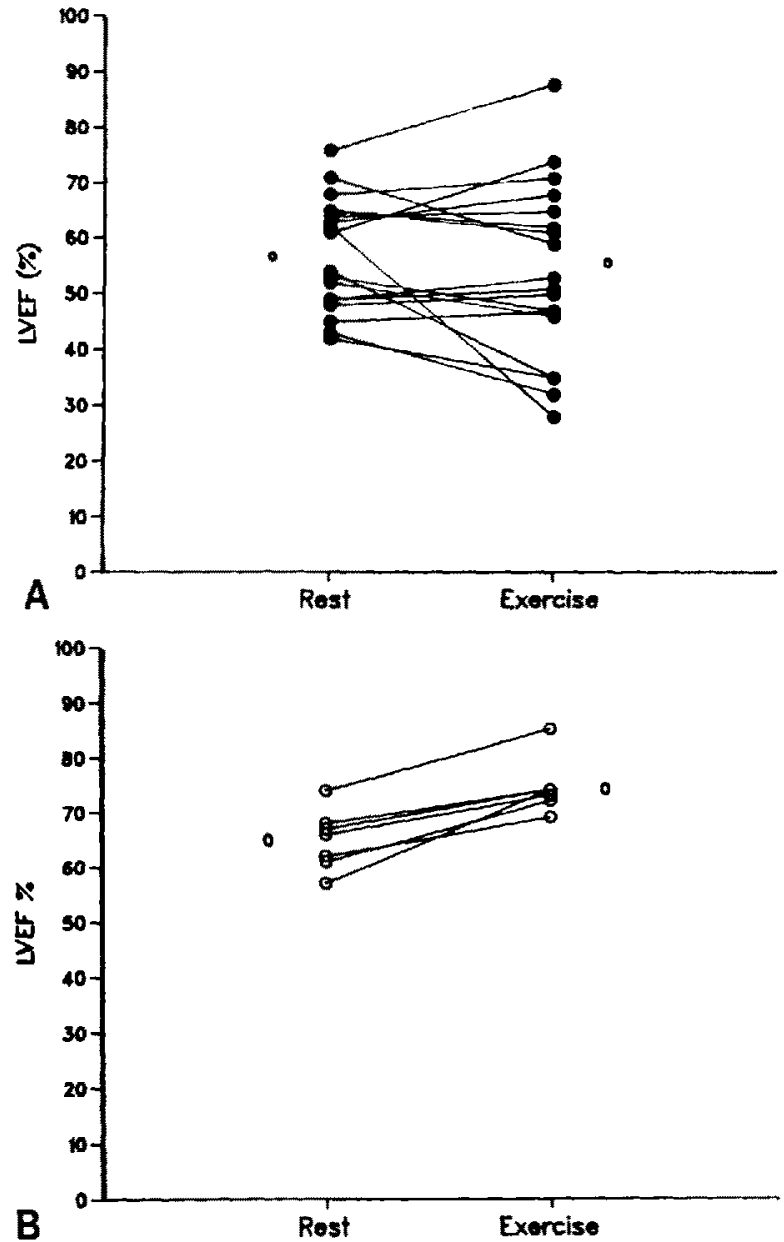

Fig. 1. A, B Results of rest and exercise radionuclide ventricular ejection fraction in patients with prior myocarditis and control subjects. A myocarditis $(n=18, P=\mathrm{NS}) ; \mathbf{B}$ control $(n=7, P<0.01)$

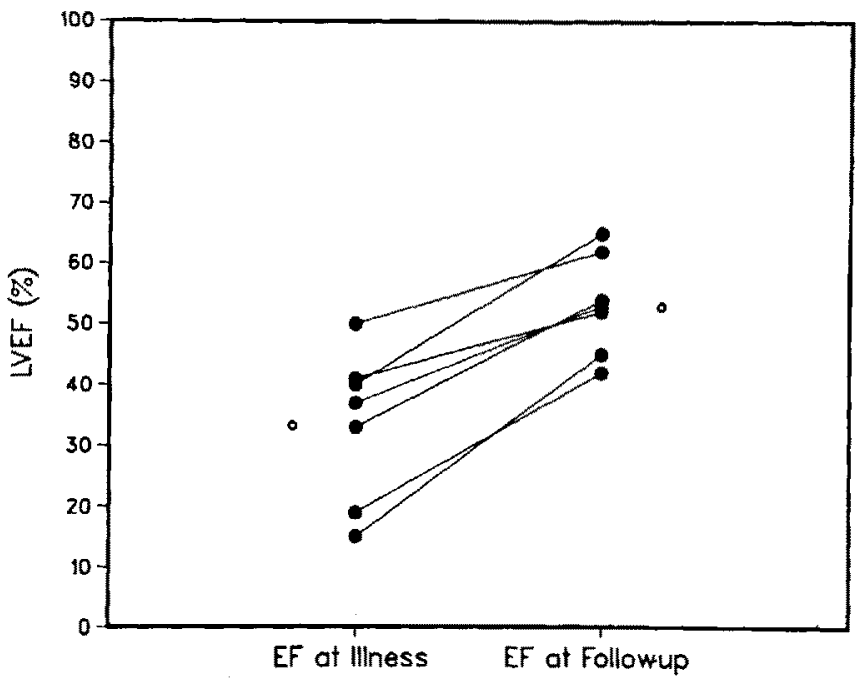

Fig. 2. Results of radionuclide ventricular ejection fraction at rest during acute myocarditis and at mean follow up of 28 months $(n=7)$

(range, 0.42-0.65) at follow-up (Fig. 2). The mean LVEF during exercise in the patients with prior myocarditis was $0.56 \pm 0.1$ compared with $0.74 \pm 0.05$ in the control group. This difference was significant $(P<0.01)$. The mean LVEF in patients with prior myocarditis showed no change during exercise compared with a significant increase observed in normal subjects $(P<0.01)$. Fourteen patients with prior myocarditis showed a decline in the LVEF with exercise (less than 0.05 increase). Regional wall motion abnormalities were noted either at rest or during exercise in only four of the patients with prior myocarditis, none of whom had significant coronary artery disease on earlier coronary arteriography. 


\section{Discussion}

One obvious shortcoming of this study and previous studies of this type concerns the uncertainty of the diagnosis of myocarditis. Although the diagnosis was not confirmed by viral or bacteriologic studies in all our patients, the clinical presentation with ancillary studies at the time of the illness was consistent with myocarditis [6]. In the absence of a reliable standard against which other tests can be compared for the diagnosis of myocarditis, reliance has to placed on the overall clinical data supported by evidence of cardiac involvement not due to recognized causes, i.e., ischemic, valvular, congenital, toxic (alcohol), and other secondary causes. Coronary artery disease as a cause of the acute illness in our patients was unlikely on the basis of clinical presentation, age, thallium-201 scintigraphy, resting and exercise RNV, and coronary arteriography.

This study confirms observations from previous studies that the long-term outlook for patients having recovered from an episode of presumed myocarditis is good [1,2]. This is in sharp contrast to that with dilated cardiomyopathy [11]. Despite the absence of symptoms in 17 of 18 patients, there were persistent abnormalities on physical examination, chest X-ray, ECG, and on M-mode echocardiograms (Table 3). Using RNV as a measure of ventricular function, a surprisingly high percentage $(33 \%)$ had abnormal resting LVEF and a higher percentage $(77 \%)$ during exercise. Dynamic exercise testing improves the likelihood of detecting subclinical abnormalities in ventricular function. Left ventricular function determined by RNV has been shown to correlate well with values determined during contrast left ventriculography, both at rest and following exercise in patients with coronary artery disease [12]. Also, abnormal RNV responses are thought to be sensitive indicators of myocardial disease of various etiologies. Of interest is the fact that despite the moderately severe impairment in resting LVEF noted in six patients during acute jllness, their followup resting LVEF improved markedly, consistent with their overall clinical improvement (Fig. 2).

The significance of impaired LVEF in our asymptomatic patients remains unclear. It probably represents residual damage from prior myocarditis. Although unlikely, the impaired LVEF could represent newly acquired coronary artery disease or other forms of myocardial disease in some of our patients. Whether these patients will eventually develop features of dilated cardiomyopathy is unknown. In this regard, we have noted late development of dyspnea in two of the patients with abnormal follow-up LVEF. One of these patients has clearly developed dilated cardiomyopathy with congestive heart failure requiring diuretics and vasodilators. There was further deterioration in left ventricular function with a drop in resting LVEF from 0.53 to 0.31 and exercise LVEF from 0.46 to 0.35 . The second patient also showed a fall in LVEF at rest and exercise as well as a further increase in left ventricular end-diastolic dimension in echocardiography. It appears that both these patients have evolved into a dilated cardiomyopathic state. No obvious cause for their clinical deterioration is evident.

It has been postulated that perhaps an autoimmune mechanism initiated by a virus and perpetuated via an autoimmune process resulting in progressive myocardial damage may be responsible [13]. Of interest are recent immunologic studies which show evidence of abnormal suppressor T-cell function as well as antibody-dependent cytotoxicity in pa- tients with myocarditis $[14,15]$. Two patients with frequent premature ventricular beats, one symptomatic during follow-up, were evaluated by right ventricular electrophysiologic stimulation. In neither case could ventricular arrhythmias be induced and they were, therefore, not treated with antiarrhythmic agents.

Our present long-term study indicates that most patients with prior myocarditis remain asymptomatic despite the fact that the majority of them have evidence of impaired cardiac function. It is unclear as to whether the abnormal function demonstrated in these patients represents a marker for future development of dilated cardiomyopathy.

\section{References}

1. Gerzen P, Granath A, Holmgran B, Zetterquist S (1972) Acute myocarditis: A follow-up study. Br Heart J 34:575-583

2. Heikkila $J$, Karjalainen $J$ (1982) Evaluation of mild acute infectious myocarditis. Br Heart J 47: 381-391

3. Burch GE, Sun SC, Colcolough HS, Sohal RS, DePasquale ND (1967) Coxsackie B viral myocarditis and valvulitis by immunofluorescent techniques. Am Heart J 74: 12-23

4. Wolff L, Grunfeld O (1963) Pericarditis. N Engl J Med 268: 419-426

5. Gormsen H (1955) Sudden unexplained death due to myocarditis. Acta Pathol Microbiol Scand, Suppl 105: 30-48

6. Sainani GS, Krompotic E, Slodki SJ (1968) Adult heart disease due to the Coxsackie virus $B$ infection. Medicine 47: 133-147

7. Das SK, Brady TJ, Thrall JN, Pitt B (1980) Cardiac function in patients with prior myocarditis. J Nucl Med 21:689-693

8. Strauss HW, Singleton R, Burow R, Rehn T, BAiley IK, Pitt B, Multiple gated acquisition (MUGA) (1977) An improved noninvasive technique for evaluation of regional wall motion (RWM) and left ventricular function (LVF). Am J Cardiol 39:284 (Abstract)

9. Borer JS, Bacharach SL, Green MV, Kent KM, Epstein SE, Johnston GS (1977) Radionuclide cineangiography of cardiac function during exercise. N Engl J Med 296: 839- 844

10. Borow RD, Strauss HW, Singleton R, Pond MP, Rehn T, Bailey IK, Griffith LSC, Nickoloff E, Pitt B (1977) Analysis of left ventricular function from multiple gated acquisition (MUGA) cardiac blood pool imaging: Comparison to contrast angiography. Circulation 56: 1024-1028

11. Fuster V, Gersh BJ, Giuliani EF, Tajik AJ, Brandenberg RO, Frye RL (1981) The natural history of idiopathic dilated cardiomyopathy. Am J Cardiol 47: 525-534

12. Walton JA, Lo KS, Brymer JF, Pitt B (1978) Exercise ventriculography: Assessment of functional significance of coronary lesions. Circulation 58:11-122 (Abstract)

13. Sanders V (1963) Viral myocarditis. Am Heart J 65: 707-713

14. Eckstein R, Mempel W, Bolte H-D (1982) Reduced suppressor cell activity in congestive cardiomyopathy and in myocarditis. Circulation 65: 1224-1229

15. Maish B, Trostel-Soeder R, Stechemesser E, Berg PA, Kochsiek $\mathrm{K}$ (1982) Diagnostic relevance of humoral and cell-mediated immune reactions in patients with acute viral myocardiopathy. Clin Exp Immunol 48: 533-545

\section{Discussion}

\section{Discussants: Das, Richardson, Rużyłlo, O'Connell}

Clinical judgment does not always correlate with biopsy findings. Gallium scanning does not necessarily correlate with evidence of inflammation in the biopsy. The importance of technique in Gallium scanning was stressed. Poor left ventricular function is due to residual myocardial damage. 